\title{
Subjectivity of Discourse Markers Containing Utterance Verbs and Subjectivity ${ }^{*}$
}

\author{
PAN Xian-jun \\ Beijing International Studies University, Beijing, China
}

\begin{abstract}
Discourse markers containing utterance verbs refer to discourse markers containing the verb of speaking "shuo" (说) which means more than just "speak". This paper puts discourse markers containing utterance verbs in one category and examines their different degrees of subjectivity. The path of semantic change of "shuo" is: utterance epistemicity - commentary. The subjectivity of discourse markers containing utterance verbs is closely related to the senses of "shuo" and forms a pattern in terms of degrees of subjectivity: evidentiality < epistemicity < commentary. From the left to the right, subjectivity becomes increasingly stronger and the focus of inter-subjectivity moves from the speaker to the addressee.
\end{abstract}

Keywords: utterance, discourse markers, subjectivity, gradation

\section{Introduction}

In Chinese, one category of discourse markers is markers containing an utterance verb which means more than "to speak/say". Like other discourse markers, these markers only have procedural meaning and do not have conceptual meaning. This study focuses on the subjectivity of this category of markers. What subjectivity features do these markers present? In what ways is the subjectivity of a marker of this kind influenced by its meaning? These are the questions this study is to discuss.

\section{Discourse Markers Containing Utterance Verbs}

Previous studies on discourse markers containing utterance verbs follow two approaches. One approach studies discourse markers containing utterance verbs as a category, the other uses case studies. Studies taking the first approach include SUN (2012), YANG and ZHAO (2013), which gave comprehensive ananyses of the definition, distribution, form, syntactic and semantic features of discourse markers containing utterance verbs. In-depth case studies, represented by DONG (2003), YUE (2011), and SHENG (2013), address discourse markers containing utterance verbs from different angles such as sources and sujectivity and have generated fruitful results.

The "discourse markers containing utterance verbs" in this paper refer to both discourse markers that contain verbs of speaking “shuo" (说), “jiang” (讲), “ti” (提), “gaosu” (告诉), “dao” (道), “yan” (言), “yu” (语), such as “bieti” (别提) and “wo gaosu ni” (我告诉你), and discourse markers containing an covert utterance verb such as “yi ju hua” (一句话). The paper uses the term "discourse markers containing utterance

\footnotetext{
* Acknowledgements: The paper is supported by a general project of Beijing Municipal Education Commission Projects in 2015 (SM201510034006).

PAN Xian-jun, professor, Ph.D., School of Chinese, Beijing International Studies University.
} 
verbs" instead of "discourse markers with utterance sense" because they are different. The scope of the term the latter is narrower and only confined to "utterance sense", while "discourse markers containing utterance verbs" are not confined to "utterance sense". For example, "shuo" has other senses apart from "utterance sense". Therefore, discourse markers containing utterance verbs are actually discourse markers containing the verb "shuo" which means more than the "utterance sense".

\section{Structural Types and Subjectivity of Discourse Markers Containing Utterance Verbs}

We collect as many discourse markers containing utterance verbs in the Chinese language as possible and divide them into the following three categories in terms of the distribution of "shuo" in these discourse markers.

$\mathrm{S}+$ shuo: ni shuo (你说), ni (hai) bie shuo (你(还)别说), ni jiu shuo (你就说); wo shuo (我说), wo gei ni shuo (我给 你说), wo gaosu ni (我告诉你)

shuo + O: bushi wo shuo ni (不是我说你), kan ni shuo de (看你说的), nin shuo ni (你说你), shuo ju nanting (buhao ting) de (说句难(不好)听的), shuo ju gongdao hua (说句公道话)

shuo $+\ldots$. shuo shihua (说实话), adj. + shuo (laoshi shuo (老实说), tanbai de shuo (坦白地说), jiandan de shuo (简 单地说等)), zong de lao shuo (总的来说), hen nan shuo (很难说), ju shuo (据说), tingshuo (听说), mei de shuo (没的说), wang...li shuo (往......里说), bu man ni shuo (不瞒你说), shuo bai/chuan/tou/kai le (说白/穿/透/开了), shuo bu hao/zhun (说不好/准), anshuo (按说)

As is known, discourse markers have no conceptual meanings in themselves. They function to establish connections between and signal relations among discourse units. Discourse markers can add a subjective meaning to the discourse. SUN and FANG (2011) divide discourse markers in Chinese language into 17 categories from a pragmatic and functional perspective. Discourse markers containing utterance verbs can be found in various functional categories, such as source-highlighting markers (e.g., jushuo 据说), elaborative markers (bushi wo shuo ni 不是我说你, yi wo shuo 依我说), topic-organization markers (huan ju hua shuo 换句话说, hua you shuo huilai 话又说回来), imperative markers (wo gaosu ni 我告诉你, ni ting wo shuo 你 听我说). But of course the majority of them are of utterance type. This kind of categorization has some value, but as the researchers themselves said, "This kind of categorization is far from exhaustive" (p. 79). Completely different and new categorizations might appear if a different perspective is taken. This paper considers discourse markers containing utterance verbs as one category and studies the subjectivity of these discourse markers and the gradation of subjectivity.

The above categorization of discourse markers containing utterance verbs into three subclasses is made purely in terms of the position of the verbs of speaking in the discourse markers. But the position of the verb of saying does not indicate the degree of subjectivity of a discourse marker. In other words, there is no correlation between the gradation of subjectivity of discourse markers containing utterance verbs and the position of the verb of speaking.

There has been much discussion on the subjectivity of language. SHEN (2001) has given a detailed elaboration on this issue, so it is unnecessary to repeat here. The language the speaker uses reflects his/her attitudes and emotions. In Japanese, for instance, the speaker's subjectivity is indicated by explicit linguistic forms. Discourse markers are no exception. Discourse markers function to connect discourse units and indicate the relations between adjacent discourse units. As they only have procedural meaning, they contribute procedural rather than conceptual meaning to the content of the utterance in which they appear, thus having no 
effect on the speaker's intended meaning. Research efforts on the functions of discourse markers have been made from different angles and produced different results. YAO (2008) summarizes four functions of discourse markers: turn-taking, topic-processing, indicating the speaker's attitude, indicating the beginning and end of a paragraph or a meaning group. A deeper analysis of these four functions reveals that the functions of "turn-taking, topic-processing and indicating the beginning and end of a paragraph or a meaning group" are not on the same level as the function of "indicating the speaker's attitude". The former three functions are all related to the organization of discourse, while the latter is about subjectivity. Sun (2012) states that procedurality and subjectivity are the two semantic features of discourse markers containing utterance verbs. Therefore, the issue of subjectivity is an important topic in the research on discourse markers, and even more so to discourse markers containing utterance verbs.

\section{Meaning and Subjectivity Differences of Discourse Markers Containing Utterance Verbs}

Why do discourse markers containing utterance verbs have different degrees of subjectivity? What is the rank order of these discourse markers in terms of their subjectivity? In order to answer these two questions, we should first make it clear that the most important verb of speaking "shuo" has more senses than "say", which directly causes the differences in the subjectivity of discourse markers containing utterance verbs. In the fifth edition of Xiandai Hanyu Cidian (also known as Contemporary Chinese Dictionary), "shuo" as a verb has six senses: (1) to express meanings; (2) to explain; (3) opinion or assertion; (4) to blame or criticize; (5) to introduce a person to another or bring two or more parties together; and (6) anaphora. The first sense, the sense of "saying" in general sense, is the most important and can include the other five senses because one can only express something by "speaking". But if we discriminate the six senses by means of strict semantic categories, we should not include the latter five senses in the first one. According to WANG (2003), there are over 100 verbs of speaking in the Chinese language, but in Mandarin Chinese, "shuo" is the most important one. Among the six senses of "shuo" listed in Xiandai Hanyu Cidian, except the third sense, the other five are all verbs. A detailed analysis of these five senses shows that they fall into three categories. Senses (1), (5), and (6) belong to one category: the category of speaking and expressing. Sense (5) is the result of speaking and expressing; sense (6) means the content of "speaking and expressing" has a referent. Sense (2) and sense (4) belongs to two different categories. Sense (2) means the speaker expresses his/her understanding of something; sense (4) means the speaker expresses his/her comments and opinions. Thus, "shuo" has three major senses: utterance, epistemicity, and commentary.

In an analysis of how "nishuo" turns into a discourse marker, SHENG (2013) describes its semantic change as follows:

$n i($ pronoun $)+s h u o($ utterance $) \rightarrow n i($ pronoun $)+\operatorname{shuo~(epistemicity)~} \rightarrow$ nishuo (a discourse marker)

SHENG's description provides a reference for us to investigate the semantic change of "shuo". As a matter of fact, the semantic change of "nishuo" is mainly about the semantic change of the utterance verb "shuo". The semantic change of "shuo" is critical to the process. As was mentioned before, apart from "shuo", contemporary Chinese has other utterance verbs such as "jiang", " $t i$ ", "gaosu", and "dao", but the frequency of these verbs is much lower than that of "shuo", and the majority of discourse markers containing utterance verbs are those that contain "shuo". Then how does "shuo" come to have all those senses? In order to answer this question, we have a diachronic investigation of "shuo". 
"shuo" appeared very early in the Chinese language. In ancient Chinese, it means "to say". For example:

(1) 非为人口吃, 不能道说, 而善著书。(《史记·老子韩非子列传》)

Hanfei was a stammerer. He was unable to speak well but excelled in writing. (Biographies of Laozi and Hanfeizi from Records of the Grand Historian)

In ancient Chinese, the most typical and frequently used utterance verb is not "shuo", but "yue" (曰). Other utterance verbs include “dào" (道), yán (言), yǔ (语), huà (话), jiăng (讲), tán (谈), shù (述)”, and so on. Another important sense of "shuo" is "to explain". Shuowen Jiezi, an early 2nd-century Chinese dictionary from the Han Dynasty (206 BC-220 AD), gives a definition of "shuo": “说 (shuo), 释也 (shì yě), 一曰谈说 也 (yì yuē shuō tán yě)". (shuo means "to explain". It also means "to discuss".) For example:

(2) 说所以明也。(《墨子·经上》)

Explanation makes things clear. (Chapter Jingshang from Mozi)

"Shuo" can also mean "to comment or discuss". Shigu 2 in Guangya (an early 3rd-century CE Chinese dictionary) gives a definition of “shuo": “说 (shuo), 论也 (lùn yě)” (shuo means “to discuss”). For example:

(3) 游于说。(礼记·少仪》)

...should study and discuss their craftsmanship. (Shaoyi from Book of Rites)

Besides, "shuo" has the sense of "to blame or admonish". For example:

(4) 六曰说。一《周礼·太祝》。“说”注为: “以辞责之”。

(Taizhu in Rites of Zhou) "shuo" is annotated as "yǐ cí zé zhî" (to blame).

The above discussion shows that the major senses of "shuo" appeared as early as in pre-Qin times and are quite similar to its senses in contemporary Chinese. Although "shuo" is a major utterance verb in contemporary Chinese, its sense of "utterance" was not frequently used in ancient Chinese. The sense of "blaming or criticizing" was used even less frequently. Our Corpus shows that the sense of "blaming or criticizing" was first used in Ming Dynasty (1368-1644) and appeared frequently in novels of late Qing Dynasty (1644-1912) and the Republic of China (1912-1949), but not in the form of "bushi shuo ni". "Shuo" in most cases means "to state, to explain"; in a few cases, it means "to criticize, to blame", which is close to the implied meaning of "bushi wo shuo ni" as a discourse marker.

(5) 不是我说句造㧛的话, 你们没有本事! (《红楼梦》)

I don't want to talk like a trouble-maker, but I don't think if you don't stick up for yourselves you can't very well blame others. (Dream of the Red Chamber)

We know that discourse markers do not have conceptual meaning and function to connect discourse units and signal the relations between adjacent discourse units. But they have procedural meaning and subjectivity. This is also the case for discourse markers containing utterance verbs. We believe that the subjectivity of these markers is closely related to the meaning of the utterance verbs. For instance, the marker "bushi wo shuo ni" conveys the message of "blame and criticism", which is actually one of the senses of the verb "shuo". For example:

(6) 不是我说你, 你这方面太差把火。

It's not that I am criticizing you, but you are so lame in this.

The marker "ni hai bieshuo" is used to express the speaker's subjectivity that the message of the following discourse exceeds his/her expectation. For instance,

(7) 你还别说, 小张说的这个, 还真不失为一条妙计。

You know what, what Xiaozhang said was a brilliant plan indeed. 
(8) 你还别说, 监狱里还有好人。

You know what, there are kind people in jail.

The verb "shuo" in "ni hai bieshuo" means "to think or believe", which is precisely the sense of epistemic sense of "shuo". Therefore, we can say that the subjectivity of discourse markers containing utterance verbs is closely related to the senses of the utterance verb "shuo".

But it should be noted that discourse markers mean something in themselves as a whole or a construction, which, in many cases, is not a simple addition of the meanings of their constituent parts. The marker "ni shuo ni" is a typical marker used to express blame. For instance,

(9) 你说你, 非把自己弄哭才算完。

Look at yourself. You are crying! Do you have to torture yourself like this?

(10) 你也干点正事儿，你说你，混成这样，一天到晚的连个正形都没有。

Don't you have a plan? Look at yourself. You are such a loser...

It is hard to determine whether "shuo" in the marker "ni shuo ni" means "to think or believe" or "to blame or criticize", but the marker as a whole expresses the subjectivity of "blame". We should also note that, in many cases, the sense of "speaking" of utterance verbs in this type of discourse markers has been weakened and grammaticalized and that the discourse markers only function to introduce the incoming discourse. The marker "wo/ni shuo" is one example:

(11) 哎, 我说, 我要是不让你喝酒吃肉, 你又能怎么样?

Hey, I say, what are you gonna do if I forbid you from drinking and alcohol eating meat?

（12）陈市长是战略家，他亲自指挥五反运动，你说，他会不会知道我们工商界的具体情况?

Mayor Chen is a strategist; he is leading the Five-Anti Movement in person. Is it possible that he knows everything about our business circle?

In these two examples, "wo/ni shuo" only serves to introduce the following discourse, and the sense of "speaking" of the verb "shuo" has been grammaticalized. In (12), "nishuo" can be interpreted as "you think" on the surface, but actually it means it is the speaker that is doing the thinking. "nishuo" is used as a marker to introduce the following discourse in which the speaker expresses his/her worry or misgivings.

\section{Subjectivity Gradation of Discourse Markers Containing Utterance Verbs}

Researchers classify discourse markers in different ways due to differences in research purposes and research methods. Fraser (1999) classifies discourse markers into two main classes: discourse markers which relate topics and discourse markers which relate messages. The second class has three main subclasses: contrastive markers, elaborative markers, and inferential markers. We will not discuss this issue in detail here. Our focus is on subjectivity gradation of discourse markers containing utterance verbs.

Discourse markers containing utterance verbs function to introduce following discourse segments. From this functional perspective, this type of discourse markers can be classified into three categories: evidential markers, cognitive markers, and commentary markers.

Intensive research has been done on the evidentiality of language or the evidentiality of the Chinese language (cf., YUE, 2014), so we will not discuss the theories on evidentiality here. The most basic function of discourse markers containing utterance verbs is evidentiality, i.e., to introduce the message that the speaker intends for the address, as in the following examples:

(13) 准确地说, 西藏是一个动物乐园, 什么动物都有。 
Tibet is precisely a paradise for animals.

(14) 说句老实话, 民主党再上台, 我们也不能不跟它打交道。

To be honest, if the Democratic Party comes into power again, we cannot avoid dealing with them.

(15) 不瞒你说, 我心里很不好受......请你原谅, 我不愿对你说假话。

To tell you the truth, I feel so terrible... Please forgive me. I don't want to lie to you.

The discourse that discourse markers containing utterance verbs introduces is the message the speaker intends to convey to the listener. Discourse markers may involve different aspects of evidentiality, such as source or nature of the message, or modality. The reason discourse markers containing utterance verbs are evidential markers largely depends on the basic sense of the utterance verbs, i.e., "to express something in words". Of course, there is more to the "something" than just the message. Message is only part of it, and discourse markers containing utterance verbs carry other functions: epistemicity and commentary.

The above discussion reveals that the epistemic and commentary functions of discourse markers containing utterance verbs are not only closely related to basic senses of the utterance verb "shuo" but also the structural meaning of discourse markers as a whole. In the following discussion, we will put our focus on the gradation of subjectivity.

Careful inspection of discourse markers containing utterance verbs reveals that the subjectivity of these markers forms a gradation according to the three senses of "shuo" that we summarized in section 3. This is schematized in: Evidentiality $<$ Epistemicity $<$ Commentary.

The degree of subjectivity increases from the left to the right. We will use three of the above examples to analyze this issue.

(13) 准确地说, 西藏是一个动物乐园, 什么动物都有。

Tibet is precisely a paradise for animals.

(8) 你还别说, 监狱里还有好人。

You know what, there are kind people in jail.

(6) 不是我说你, 你这方面太差把火。

It's not that I am criticizing you, but you are so lame in this.

Example (13) only states a fact and conveys a message in an objective manner. In Example (8), " $n i$ hai bieshuo" does not mean the addressee is going to speak or the speaker asks the addressee to speak, but that the speaker is talking about his/her feelings or understanding toward a situation or event. So its subjectivity is obviously stronger than "zhunque de shuo" in Example (13). "bushi wo shuoni" in Example (6) means the speaker's evaluation and judgment about the listener. It expresses dissatisfaction and reproach, thus having the highest degree of subjectivity. These three examples show that the subjectivity of these discourse markers containing utterance verbs forms the gradation of "Evidentiality $<$ Epistemicity $<$ Commentary".

Why does the subjectivity of discourse markers containing utterance verbs have this pattern? All linguistic forms have subjectivity, discourse markers are of no exception. This is a common understanding in the field of linguistics. The subjectivity gradation of these markers is closely related to intersubjectivity: Intersubjectivity also increases from the left to the right.

Evidentiality $<\underset{\text { Epistemicity }<}{<}$ Commentary
Subjectivity

Inter-subjectivity involves the speaker's attention to the addressee. According to YAO (2008), the mechanisms of subjectification and intersubjectification are different. In subjectification, the meaning of the 
utterance is more strongly directed towards the speaker, while in intersubjectification, the meaning of the utterance is more strongly directed towards the addressee. Apparently, the stronger the intersubjectivity is, the stronger the subjectivity is. This is reflected in the subjectivity of discourse markers containing utterance verbs. Pure evidential markers display subjectivity in general: "tingshuo" (听说) indicates the source of information, “shuo shihua” (说实话) and “tanbai de shuo" (坦白地说) indicate the speaker's attitude, “zhunque de shuo"(准 确地说) means the message is reliable, “shuo kai le" (说开了) and "shuo chuan le" (说穿了) indicate the amount of information given by the speaker. When discourse markers containing utterance verbs are used as epistemic markers, there is an increase in the speaker's subjectivity, reflecting the speaker's understanding of a situation or event, which is definitely from the speaker's point of view. Kuno (1987) argues that a speaker's description of a situation is definitely made from a certain point of view or camera angle. Thus, discourse markers containing utterance verbs that have epistemic function direct the meaning of the utterance towards the speaker, resulting in a stronger subjectivity than evidential markers. Of course, what makes an utterance truly inter-subjective and the meaning of an utterance more directed towards the addressee is those markers with commentary function. Markers such as "bushi wo shuo ni" and " $i$ shuo ni" express the speaker's blame, complaint, and criticism to the addressee. The meaning of the utterance is focused on the addressee. In many circumstances, empathy incorporated in the utterance makes it mild and more acceptable to the addressee. This is how discourse markers containing utterance verbs form the above gradation in subjectivity.

\section{Conclusion}

From the above analysis, we come to the conclusion that discourse markers containing utterance verbs have different degrees of subjectivity because of the different meanings of utterance verbs, forming a gradation of Evidentiality < Epistemicity < Commentary, in which the subjectivity becomes increasingly stronger from the left to the right.

\section{References}

DONG, X. F. (2003). Lexicalization of “X shuo". Language Science, 2, 46-57.

Fraser, B. (1999). What are discourse markers? Journal of Pragmatics, 31, 931-952.

Kuno, S. (1987). Functional syntax: Anaphora, discourse and empathy. Chicago: The University of Chicago Press.

SHEN, J. X. (2001). Subjectivity and subjectification of language. Foreign Language Teaching and Research, 2, $268-275$.

SHENG, J. Y. (2013). Discourse marker “nishuo". Chinese Language Learning, 3, 31-36.

SUN, L. P. (2012). Basic characteristics of Chinese discourse markers containing utterance verbs. Jinan Journal, 4, 138-145.

SUN, L. P., \& FANG, F. M. (2011). Overview of study on types and functions of Chinese discourse markers. Chinese Language Learning, 6, 76-84.

WANG, W. H. (2003). Diachronic evolution and synchronic distribution of "shuo-type verbs" in Chinese. Chinese Philology, 4 , 329-342.

YANG, C. Y., \& ZHAO, CH. L. (2013). Syntactic and semantic features of discourse markers containing utterance verbs. Chinese Linguistics, 3, 75-84.

YAO, Zh. L. (2008). Subjectification of "shuo, xiang, kan" and its causes. Language Teaching and Research, 5, 47-53.

YUE, Y. (2011). Interaction of subjectivity and pragmatic principles in conversations from the perspective of the discourse markers containing "bushi wo shuoni". Chinese Teaching in the World, 1, 69-77.

YUE, Y. (2014). Nature and general picture of evidentiality in contemporary Chinese. Linguistic Research, 2, 27-34. 